\title{
Un balance del ciclo progresista en América Latina'
}

Maristella SUAMPA

SUMILLA

Partiendo de varias epistemologías con origen en el Sur, la aproximación a la crisis de Brasil, a la coyuntura desfavorable, de poca legitimidad o de reducida aceptación de los gobiernos progresistas de nuestra América es analizada a través de tres ejes críticos: el ecoterritorial, el socioeconómico y el político institucional. Es importante destacar que el análisis mediante estos tres ejes permite aproximarnos a un entendimiento de la región en su conjunto, previo balance de los gobiernos progresistas en la región a quince años de su emergencia.

PalabRAS ClavE: commodities, populismo, lucha indígena, neodependencia, ex-tractivismo

\section{A balance of progressive cycle in Latin America}

\begin{abstract}
Taking into account the several epistemologies located at the South, the approach to the Brazilian crisis, the approach to the delegitimization or the decreasing political acceptance of the Latin American welfare-oriented government have been analyzed through three critical areas: the eco-territorial, the socioeconomic and the institutional policy. Those critical areas are useful as well to approach an understanding of the region as a whole, after studied the fifteen years of the Latin American welfareoriented government hegemony.
\end{abstract}

KEYWORDS: commodities, populism, indigenous struggle, neodependency, extractivism

1 Conferencia magistral presentada en el XXXII Aniversario de la Facultad de Ciencias Sociales de la Universidad Nacional Mayor de San Marcos el jueves 22 de setiembre de 2016. 
$\mathrm{B}$ uenos días a todas y a todos. Gracias por la invitación. Es un honor estar acá en Lima y en la histórica y gran Universidad Mayor de San Marcos. Nunca había estado acá en este maravilloso campus. Así que, estoy muy contenta de esta invitación. Espero que sea el comienzo de un rico intercambio entre nuestras perspectivas.

Quisiera hacer una presentación en tres movimientos. En primer lugar, doy cuenta de algunas consideraciones preliminares. En segundo lugar, desarrollo cuáles son los ejes que, desde mi perspectiva, nos pueden ser útiles para entender la América Latina de hoy. Y, en tercer lugar, realizo un balance del ciclo progresista, al menos, en lo que respecta a algunos países del denominado tan genéricamente "ciclo progresista". Para ello, presentaré tres críticas centrales, la ecoterritorial, la socioeconómica y la políticoinstitucional y dos comentarios finales, en clave geopolítico, referido al regionalismo desafiante y los vínculos con China.

\section{Consideraciones preliminares}

Respecto de las consideraciones preliminares, éstas son al menos tres. En primer lugar, la perspectiva epistémica que yo desarrollo en distintos escritos, pero que vale la pena destacar. A mí me gustaría insistir que hay, por lo menos, tres perspectivas críticas que en América Latina confluyen, desde una perspectiva epistémica diferente. Una es la línea crítica a la colonialidad del poder y la colonialidad del saber. Se trata de un patrón de dominación mundial, leído no sólo en clave étnica racial, sino también epistémica o epistemológica. Tanto los aportes de Aníbal Quijano, como los de Edgardo Lander resultan muy importantes ${ }^{2}$. También rescato como segunda perspectiva aquella que proviene de los estudios subalternos, del campo poscolonial y que ilustra los trabajos de la boliviana Silvia Rivera Cusicanqui ${ }^{3}$, quien considera que, efectivamente, en América Latina el peso del colonialismo es estructural; y ha fijado estructuras de dominación en la propia subjetividad de las personas, de los sujetos. Pero esas estructuras de colonialidad son refuncionalizadas en clave de opresión política y en clave de nuevas formaciones políticas, también. Es importante destacar que en esa línea del subalternismo radical hay muchos trabajos en América Latina que dan cuenta de una reconstitución, de las acciones de los sectores subalternos desde abajo. Son las voces bajas de la población, los grandes actores sociales silenciados. Una tercera perspectiva es aquella que asociada a los trabajos de Boaventura de Sousa Santos ${ }^{4}$, que ustedes deben conocer porque transita mucho por América Latina. Yo siempre

2 Al respecto véase Lander, Edgardo. La colonialidad del saber. Buenos Aires: CLACSO. 1993.

3 Cusicanqui, Silvia Rivera. Debates poscoloniales. La Paz: Aruwiyin. 1997.

4 De Sousa Santos, Boaventura. Conocer desde el Sur. Lima: PDTG. 2006 
digo que viene de un país semiperiférico, pero en todo caso la "epistemología del sur" que él propone no menta una realidad geográfica, sino más bien cuestiones de índole política respecto de las relaciones Norte-Sur. Por esa razón, Boaventura pone el acento en el hecho de que no puede haber una justicia social global sin una justicia cognitiva, también, a nivel global. Pero, en todo caso, estas tres vías epistémicas que hoy encontramos muy implantadas en América Latina buscan dar visibilidad y credibilidad a las prácticas cognitivas de los pueblos, de los grupos sociales, de las clases históricamente subalternas históricamente oprimidas.

Dicho esto hay una segunda consideración preliminar que a mí me interesa traer aquí porque permea la visión crítica que voy a presentar, y está vinculada al rescate de una visión más eco-marxista que subraya la doble dinámica o la doble contradicción del capital. Como todos sabemos, cada vez que se lee a Marx ${ }^{5}$ se suele subrayar la contradicción fundamental que opone el capital al trabajo. De allí que haya ciertas problemáticas como la del desempleo, la explotación, la sobre explotación, más aún la marginalidad, que están ligadas a esta contradicción, que coloca el acento en la tasa de explotación o plusvalía. Sin embargo, olvidamos que hay una doble dinámica del capital, pues ésta también debe ser leída a partir de la contradicción que se establece entre el capital y la naturaleza, una segunda contradicción que, en general, es invisibilizada. En el marco del capitalismo avanzado el capital avanza consumiendo más materia y energía, lo cual hace que la presión sobre los bienes naturales cada vez mayor. El capitalismo avanza a través de la apropiación económica y destructiva de la naturaleza y el ambiente $y$, por ende, de los bienes naturales. Es así que vamos a encontrar una serie de problemáticas ligadas a esta segunda contradicción del capital, como dice James $\mathrm{O}^{\prime} \mathrm{Connor}^{6}$, ligada a los modelos de ocupación territorial por parte de los grandes capitales transnacionales.

Esto constituye una diferencia fundamental a la hora de abordar el pensamiento crítico latinoamericano, porque no todos los autores están dispuestos a retomar la segunda contradicción del capital; antes bien, suelen de manera unidimensional subrayar sobre todo la primera contradicción del capital y atenerse o acotar sus análisis de los conflictos a esa cuestión. Por eso, efectivamente, me parece importante subrayar esta tendencia a la unidimensionalidad de los análisis que dan cuenta, podríamos decir, de una suerte de fractura del pensamiento político, intelectual latinoamericano a la hora de analizar y hacer un balance del llamado ciclo progresista. Durante los años noventas, en el marco del neoliberalismo, todos acordaban, todos estábamos de acuerdo, pero en el contexto vivido desde dentro de los gobiernos progresistas se ha ido estableciendo una fuerte división y fractura al interior del pensamiento

5 Marx, Karl. El capital. México: FCE. 1999.

6 O'Connor, James. Natural causses: Essays in Ecological Marxism. NY: Guilford Press. 1997. 
latinoamericano, que ha dejado hondas heridas. Se que esto es difícil de comprender desde el Perú, porque el Perú no ha conocido, no ha tenido la experiencia de los gobiernos progresistas, pero es bueno tener en cuenta esta fractura que se ha dado al interior del progresismo.

\section{Cuatro claves para leer América Latina}

El segundo eje que me interesa subrayar, antes de pasar a hacer un balance de los gobiernos progresistas, comprende cuatro ejes claves, desde mi perspectiva, para leer la situación hoy en América Latina. Seguramente hay otras más, pero desde mi perspectiva creo que estas son relevantes para dar cuenta de la configuración de ciertos escenarios políticos en América Latina, de mucha actualidad. El primer eje es el avance de las luchas indígenas y la reflexión acerca del lugar de los pueblos originarios en el marco del Estado-Nación. El segundo eje aborda la expansión de los modelos extractivistas en el marco de la segunda contradicción del capital. El tercero refiere a la reactualización de la figura de la dependencia, tan cara en nuestro pensamiento y realidad. Y, la última, con el retorno de los populismos en América Latina. Voy a decir, brevemente, algunas cosas para contextualizar cada una de ellas.

La primera clave se refiere al avance de las luchas indígenas. Ayer el profesor Rodrigo Montoya evocaba el rol del katarismo en Bolivia ${ }^{7}$, que es conocido como la primera emergencia indígena en América Latina en los setenta. En el noventa, Bengoa, el historiador chileno, sitúa la segunda emergencia indígena que tiene que alude al empoderamiento creciente de los pueblos originarios a nivel organizativo, así como al reconocimiento de los derechos colectivos, territoriales de los pueblos indígenas a nivel internacional. El Convenio 169 de la OIT (1989) y más adelante la Declaración de los derechos Universales de los pueblos originarios (2007). Hay ahí cuestiones nodales que es necesario desentrañar y dar cuenta, de manera diferente, en los escenarios, porque no se trata, solamente, del reconocimiento de derechos culturales, sino también de la autodeterminación. El reconocimiento de la autonomía como proyecto político implica el control de los pueblos originarios al interior de sus territorios. Y esto implica control, por ejemplo, de los recursos o los bienes naturales que hay en los mismos, pero también conlleva el reconocimiento de la justicia comunitaria y otras formas de organización propia de los pueblos originarios. Uno podría decir que, en el extremo de la fase ofensiva, la ilustración más acabada del proyecto político de los pueblos originarios se sintetiza en un concepto que, en México, en

7 Hace referencia a la conferencia: Montoya, Rodrigo. Reflexiones sobre la política en Brasil, Venezuela y Bolivia. El miércoles 21 de setiembre de 2016, en el marco del XXXII Aniversario de la Facultad de Ciencias Sociales de la Universidad Nacional Mayo de San Marcos.

\section{4/ REVISTA DE SOCIOLOGGía 26}


Ecuador y, mucho más, en Bolivia aparece sintetizado con el término "autonomía y estado plurinacional". Podríamos decir, que en el otro extremo, lo que sintetiza la fase defensiva de los pueblos originarios ante el avance de los megaproyectos extractivos es el reclamo del derecho de consulta previa, libre e informada. Dos extremos; uno por la positiva, el gran proyecto político de los pueblos indígenas en la autonomía y, el otro, el proyecto, en términos defensivos, es sin duda reclamar el derecho de consulta.

La segunda clave es la crítica del desarrollo, que recorre el pensamiento latinoamericano y las luchas sociales contemporáneas. Ustedes saben que la noción de desarrollo tiene una larga historia en América Latina, porque es uno de esos conceptos-límites que ha marcado el pensamiento social desde la CEPAL, con Prebisch y Celso Furtado, pasando por los dependentistas hasta la actualidad, el Desarrollo ha sido una de esas ideas fuerzas que sigue transitando el pensamiento y la política latinoamericana. Uno podría decir que, efectivamente, son muchos los actores involucrados, son muchos los escenarios y las escalas, a nivel local, regional, nacional e internacional, pero, en todo caso, uno puede establecer ciertos campos problemáticos mínimos. Quisiera destacar tres de ellos que nos sirven para hacer la lectura de lo que está sucediendo hoy en América Latina. El primero asocia la idea de desarrollo con la de progreso, cuyo resultado es la consolidación de un paradigma productivista que pone el acento en la noción de crecimiento económico indefinido, como si los bienes naturales no fueran agotables. Esta ideología reduccionista por la vía económica o economicista, sin duda, hoy continúa siendo predominante todavía en América Latina. Hay otro campo problemático que está siendo abordado en América Latina, particularmente desde la antropología, y es aquel que se establece entre desarrollo, sociedad y naturaleza. Sabemos que en occidente existe una división entre sociedad y naturaleza. Para decirlo de otro modo, lo que se ha instalado en occidente, desde René Descartes en adelante es una visión antropocéntrica, donde la naturaleza es vista como una canasta de recursos, como un capital, donde el hombre se percibe como algo exterior a la naturaleza a la cual debe controlar y dominar. Esta idea de exterioridad es, básicamente, cuestionada desde otros paradigmas holistas o relacionales que, por ejemplo, algunos pueblos originarios presentan, en donde hay, además de esta visión productivista, además de esta visión antropocéntrica, un plus netamente latinoamericano. Y es que en América Latina, desde hace siglos, sostenemos la idea de que nuestro continente es un gran reservorio de recursos naturales. Esos recursos naturales, desde la época de Potosí, los diferentes bienes naturales, desde el oro y la plata, luego el guano, más adelante serán el petróleo y el gas, hoy también es la soya, recursos demandados por el mercado internacional, y que al calor de los diferentes ciclos económicos, posibilitan en América Latina una suerte de bonanza económica. Así se genera una visión "eldoradista" que sostienen un pensamiento casi mágico 
que considera que América Latina, a través de la explotación desmedida de esos bienes naturales, podrá llegar a desarrollarse, acortando la brecha con los países más desarrollados. Es increíble pero, en América Latina, la contracara del imaginario del saqueo, que da cuenta de la historia de Potosí en adelante, es la ilusión desarrollista desenfrenada, la fiebre doradista, que encontramos en muchos de nuestros países.

Sin duda ha habido muchas discusiones sobre el desarrollo porque el pensamiento ambiental de los años setenta ha introducido no sólo matices, sino que ha cuestionado esta visión reduccionista, pero en la actualidad, a partir del año 2000, hay un retorno de esta visión hegemónica del desarrollo que se ha instalado en la política de nuestros países en base a estos tres ejes: productivismo, visión antropocéntrica y visión eldoradista. Además, tradicionalmente en América Latina las izquierdas, sean clasistas, sean desarrollistas, sean populistas, han sido muy refractarias al pensamiento ambiental. En general, la izquierda ha tendido a creer en el progreso bajo la forma de la expansión de las fuerzas productivas. Y la contracara es la desatención de aquellos conflictos que hoy cuestionan la relación entre capital y naturaleza.

Una tercera clave refiere a la dimensión geopolítica, lo cual nos trae el eco de la problemática ligada a la dependencia. Efectivamente, uno de los grandes temas en América Latina, entre fines de los sesenta y comienzos de los setenta, fue la reflexión sobre la dependencia, esto es, la inserción subordinada de América Latina en el contexto internacional y la importancia que adquieren las relaciones de dominación, entre centro y periferia. En la actualidad — lo que nosotros observamos - hay una actualización de esquemas neodependentistas, que tienen que ver con la continuidad de una geografía de la extracción, por parte de los países del Sur, en el marco de la división internacional del trabajo. Esta extracción en América Latina está orientado a la exportación, hacia los países a centrales y emergentes, sean minerales, sea petróleo, sea soya. En Europa se ha consolidado la tendencia a externalizar los impactos ambientales en los países del Sur que se hacen cargo de los costos (energía, agua) e impactos en los ecosistemas y en las poblaciones. Hay algunos países como Estados Unidos y China que sintetizan esta geografía de la extracción y esta geografía del consumo, pero lo que extraen está orientado hacia el consumo interno. En todo caso, lo que queda claro es que ha habido mutaciones geopolíticas importantes en los últimos quince años, que es necesario leer en clave latinoamericana. Yo creo que eso está directamente relacionado a procesos de transición hegemónica que colocan a China en un lugar fundamental, aún por indagar.

La cuarta clave, que cuenta con una larga y controversial historia en América Latina, tiene que ver con los populismos, una categoría sumamente debatida y disputada en el campo político. Ustedes, como peruanos, lo conocen muy bien, también, si remitimos a la larga y ajetreada historia del APRA o incluso al populismo militar de Velasco Alva-

\section{6/ REVISTA DE SOCIOLOGíA 26}


rado. En todo caso importa destacar el debate político y académico. En esa línea, me interesa establecer diferencias, ya que existe una visión reduccionista del populismo visible, sobretodo, en el pensamiento de la derecha y difundida por los grandes medios de comunicación, que identifican el populismo con mera demagogia, clientelismo y dilapidación de los recursos económicos. Pero, también, hay debates muy interesantes en la academia, sostenidos por numerosos intelectuales políticos latinoamericanos, que han buscado dotar de complejidad al populismo considerando que este es una especificidad latinoamericana, y que lejos de ser simple, el populismo, es un fenómeno complejo y ambivalente. Mi perspectiva apunta a subrayar esta ambivalencia del populismo, definido por la tensión insoslayable entre elementos democráticos y elementos autoritarios. Y en este sentido, es necesario leer esta oscilación que a lo largo de un ciclo. En todo caso, si analizamos el ciclo progresista, los gobiernos que considero populistas, no lo han sido de la noche a la mañana. Salvo el caso de Venezuela, quizás, que desde el comienzo fue considerado como un gobierno típicamente populista; al compás de determinados hechos políticos, ha ido evolucionando hacia el populismo, y eso es lo que queremos explicar en esta presentación.

\section{Balance del ciclo progresista}

Dicho lo anterior, quisiera abordar la segunda parte de mi presentación para un primer balance del ciclo progresista del 2000 al 2016. Algunos colocan el inicio del ciclo en 1999 que es el año que Hugo Chávez accede al gobierno en Venezuela. Yo coloco el 2000, que remite a la inflexión operada por la guerra del agua, en Cochabamba, Bolivia. En todo caso, entre los años 1999 y 2002 se opera, en América Latina, un cambio de época, que implica un cuestionamiento del neoliberalismo. Dicho cambio de época está asociado a la acción y movilización de los movimientos sociales antineoliberales, muchos de ellos de corte indígena-campesino y otros netamente policlasistas, según los países. Efectivamente, fue la lucha de estos movimientos sociales antineoliberales los que abrieron la agenda política en los distintos países latinoamericanos para pensar la relación entre economía, sociedad y política desde otra perspectiva. Ellos abrieron la agenda y posibilitaron la emergencia de los Ilamados gobiernos progresistas, los cuales se caracterizarían por tres elementos: la aplicación de políticas heterodoxas desde el punto de vista económico, la orientación social y el latinoamericanismo.

La noción de progresismo es muy genérica. El término se remonta a la Revolución Francesa y hace referencia a que los sectores progresistas son aquellos con una vocación por el cambio y la trasformación social; algunos plantean su asociación con una perspectiva social demócrata. Desde mi perspectiva, pese a la amplitud, el 
término es adecuado, porque no nos permite confundir y hablar desde el comienzo de izquierdas o nuevas izquierdas, sino genéricamente de gobiernos orientados hacia el cambio social, cuyas potencialidades y límites es necesario leer en clave de ciclo político. Además, es cierto que hay diferencias entre los llamados gobiernos progresistas: algunos se han caracterizado por una política de mayor radicalidad, ligado a los procesos constituyentes que vivieron países como Ecuador y Bolivia, incluso Venezuela; otros mucho menos, son más clásicos y tradicionales, como es el caso de la Argentina y Brasil, y mucho más Uruguay y Chile.

El ciclo progresista se caracteriza por una fuerte reducción de la pobreza. Datos de la CEPAL muestran que entre 2001 y 2012 en toda América Latina hubo una reducción de la pobreza, que pasó del $44 \%$ a 31\% y la pobreza extrema, que pasó del $19 \%$ al $12 \%$. Sea que hablemos de gobiernos conservadores, neoliberales o gobiernos progresistas, todos ellos implementaron políticas de bonos o de planes sociales. Tal es así que, también, si tomamos otro documento de la CEPAL de 2012, este indica que el 19\% de la población latinoamericana está bajo planes, lo cual, más o menos, abarca ciento trece millones de personas. Sin duda fue el crecimiento económico ligado al "boom de los commodities".

Eso nos permite introducir otro concepto, "el consenso de los commodities". Los commodities son aquellas materias primas o productos con escaso valor agregado, que tienen un precio estandarizado en el mercado internacional. En este sentido, hablo de consenso de los commodities para señalar el pasaje que se ha dado en los últimos quince o veinte años, el cual indica el tránsito en América Latina del consenso de Washington al consenso de los commodities. Hemos pasado de un período centrado en la valorización financiera, caracterizados por procesos de ajuste y de reestructuración del Estado, que implicaron altos niveles de exclusión, a un modelo centrado en la extracción de materias primas orientadas al mercado externo, cuyas consecuencias sociales y ambientales, son claramente minimizadas por gran parte de los gobiernos de la región, sean estos gobiernos conservadores, o sean estos progresistas. Así, en función de las ventajas comparativas, debido a los altos precios de los commodities, la mayor parte de los gobiernos hicieron caso omiso a las resistencias sociales que fueron erigiendo en los distintos territorios, pero también a las críticas, que desde la investigación científica independiente, se hacían sobre las consecuencias sociosanitarias, ambientales, incluso también culturales y políticas, que vienen engendrando estos megaproyectos de carácter extractivo.

Desde mi perspectiva el consenso de los commodities, habla del ingreso a una nueva época, y no hace solamente alusión a un nuevo orden económico, sino también nos inserta de manera más clara en un orden, podríamos decir, político e ideológico diferente, porque hay un discurso hegemónico, sea de la mano de go- 
biernos progresistas o neoliberales, de suturar la discusión acerca de las alternativas o de modelos alternativos, en nombre de la dinámica irresistible del extractivismo. Dicho de otro modo, así como en la década del noventa, el neoliberalismo emergía como un discurso único, en la actualidad, el extractivismo aparece como una suerte de único camino, de discurso único, pues no habría alternativa posible al mismo, con lo cual las resistencias quedarían del lado de los "fundamentalismos", descalificadas y consideradas como irracionales o inviables.

El consenso de los commodities señala una gran paradoja durante el ciclo progresista, pues, por un lado asistimos a una expansión de la frontera de derechos, derechos sociales, derechos colectivos, derechos territoriales, como los vemos en las nuevas constituciones políticas en Ecuador, en Venezuela, en Bolivia; pero, por el otro lado, hay una expansión de las fronteras del capital a través del avance sobre los territorios mediante una serie de actividades extractivas a gran escala. Con el afianzamiento del consenso de los commodities, los gobiernos progresistas buscarán ocultar o invisibilizar el proceso de desposesión de tierras y territorios y la inevitable conflictividad que esta dinámica desata en América Latina. La megaminería es un caso emblemático de conflictividad extractiva en el marco del Consenso de los commodities. No solamente en el Perú hay conflictos por el tema de la megaminería, por ejemplo, los hay en todos los países de América Latina; también hay conflictos petroleros y por la expansión de la frontera petrolera, conflicto de la frontera energética, conflicto por la expansión de los monocultivos como el agronegocios. En fin, la expansión del extractivismo y la conflictividad socioambiental han sido una de las notas fundamentales del período.

Desde ese punto de vista, uno podría decir que, con quince años del ciclo progresista, es posible hacer ya un balance de este ciclo. No es lo mismo el 2005 o el 2008 que el 2016. Mucha agua ha corrido bajo el puente, también muchas promesas incumplidas. En ese sentido, efectivamente, se han ido consolidando una serie de críticas muy fuertes a los procesos ligados a los gobiernos progresistas. En esta línea destaco tres tipos de críticas mayores: la crítica ecoterritorial, la crítica socioeconómica y la crítica político-institucional.

Respecto de la crítica ecoterritorial, a lo dicho quiero añadir lo siguiente. La crítica ecoterritorial se refiere al extractivismo, pero yo diría que es una crítica que se realiza no sólo en clave territorial sino en clave civilizatoria, a través de nociones como la de neoextractivismo, como la de consenso de los commodities, como la de mal desarrollo. Asimismo, recordemos que la demanda de bienes naturales ha producido que América Latina, nuevamente, se ha especializado en la exportación de unos pocos productos, sea de minerales, sea de petróleo, sea de soya o inclusive también de energía. Este proceso de reprimarización ha implicado mayor dependencia. 
La crítica ecoterritorial también coloca énfasis en los conflictos y en los procesos de criminalización de las resistencias. Es importante destacar que si bien ha habido un afán de invisibilizar los conflictos territoriales que se han dado en Bolivia, en Ecuador, en Argentina, o en otros países con gobiernos progresistas, éstos finalmente han terminado por tener cierta visibilidad. Pese a que existen una gran cantidad de conflictos socioterritoriales, la mayoría queda encapsulada en lo local y son pocos los que adquieren visibilidad a nivel nacional, como ha sucedido con el proyecto Conga, acá en el Perú. Cada país tiene su conflicto emblemático: el Tipnis en Bolivia, el conflicto minero de Famatina en Argentina, el Proyecto Yasuni en Ecuador, la represa de Belo Monte en Brasil, el canal de Nicaragua en ese país. Todos ellos han generado una respuesta virulenta por parte de los gobiernos progresistas, que ha venido acompañada de las más variadas hipótesis conspirativas acerca de quiénes están detrás de los actores que se movilizan cuestionando megaproyectos extractivos. Esto ha implicado mayor criminalización de la protesta social, mayor bastardeo y manipulación de los dispositivos institucionales que están previstos en nuestras constituciones - desde el Convenio 169 de la OIT hasta las consultas públicas - y que, en general, se obturan para que los pueblos no puedan decidir acerca de los distintos proyectos. A su vez, ha habido en Ecuador y Bolivia lo que podríamos denominar un proceso de "vampirización" de ciertos conceptos asociados a los procesos constituyentes como el de derecho de la naturaleza, o el de buen vivir, o el de vivir bien.

Es cierto que estos conflictos ecoterritoriales no tienen el mismo grado de centralidad en sus países, en algunos son más centrales, en otros más periféricos, pero todos ellos colocan o tratan de poner a la luz otra agenda de derechos humanos que, por lo general, es invisibilizada. A su vez, el aumento de la conflictividad ha venido probando el correlato de más extractivismo es menos democracia.

Quiero subrayar también que la crítica ecoterritorial está ligada no sólo a la emergencia de un pensamiento ambiental, sino sobre todo a movimientos ecoterritoriales que son portadores de una nueva gramática política. Una gramática política que expresa nuevos conceptos que permiten pensar la relación entre sociedad y naturaleza desde otro eje, desde otra racionalidad ambiental, como son los ya citados de buen vivir y derecho a la naturaleza, pero también están el concepto de bienes comunes, el de justicia ambiental, y de ética del cuidado, un concepto tan importante dentro de la lógica del feminismo.

La segunda crítica es de índole socioeconómica. Si la crítica ecoterritorial fue la primera en agrietar el discurso progresista, yo diría que la crítica socioeconómica quizá ha sido la más tardía. La crítica socioeconómica lo que subraya es que en realidad estos gobiernos, sea que hablemos de Ecuador, de Venezuela, de Argentina, de Brasil, no han producido una transformación de la matriz productiva. No han producido una transformación de las estructuras sociales. Por supuesto que existen efectos de

\section{0/ REVISTA DESSOCOLOGGíA 26}


democratización muy importantes. Destaco el caso de Bolivia — voy a volver hacia el cierre en ello- pero básicamente las promesas de cambio de matriz productiva y de transformaciones estructurales quedaron en lo meramente discursivo y lo que hemos encontrado es más bien reprimarización de la economía. Creo que el caso de Venezuela, país rentista, que hoy pasa por su crisis más aguda, ilustra cabalmente esta dificultad en transformar la matriz productiva.

Tampoco hubo en los países con gobiernos progresistas una reforma tributaria fiscal. Se optó básicamente por captar la renta extraordinaria, tanto petrolera como minera, según los casos. No hubo una reforma fiscal que tocara los intereses de los sectores más ricos. Los sistemas fiscales o tributarios en América Latina siguen siendo bastante opacos y regresivos, en el sentido que se basan mucho en los impuestos indirectos que paga el conjunto de la población. Los últimos trabajos o investigaciones en América Latina también han insistido en la idea de la ausente reducción de las desigualdades, aunque si ha habido una reducción fuerte de la pobreza. La reducción de la pobreza aparece vinculada a la creación de empleo, al mejoramiento de los salarios, a la inclusión a través del consumo, pero no a una redistribución de la riqueza. Antes bien, hay una concentración mayor de la riqueza en América Latina. Al final del boom de los commodities encontramos que los ricos se han consolidado, mientras que los pobres se han hecho un poco menos pobres.

La tercera crítica alude a lo político-institucional. Y esta es la crítica que trae a colación la temática del populismo, que nos advierte de la relación entre gobiernos progresistas y populismos. En realidad, hasta el año 2006 o 2007 en América Latina se hablaba de izquierdas latinoamericanas. Sin embargo, hoy en día se habla de populismos. En el pasaje de una categoría a otra es mucho lo que se ha perdido la confianza que estos regímenes promovieran, efectivamente, una transformación de sus estructuras sociales y políticas. Como ya he señalado, el populismo es un concepto controversial, muy manipulado por la derecha; por lo cual hay que tener mucho cuidado cada vez que se lo trae a la escena política. Pero, efectivamente, en el marco de una concepción crítico-comprensiva, podemos definirlo a partir de la oscilación entre los elementos democráticos y los elementos autoritarios. Esto se manifiesta en la consolidación de los liderazgos personalistas, que suelen acentuar los esquemas hiperpresidencialistas que están presentes en nuestras constituciones, e implican altos niveles de concentración del poder político. Esto es importante subrayarlo porque la izquierda siempre critica la concentración de poder económico, pero muchas veces se olvida de criticar la concentración de poder político. La mayor parte de los gobernantes considerados progresistas, han buscado perpetuarse en el poder. Buscó hacerlo Chávez y lo logró, con el segundo referéndum. Buscó hacerlo Cristina Fernández de Kirchner y en 2013 la movilización social le dijo que no. Lo mismo que ha sucedido 
de manera clara con el referéndum que perdió este año Evo Morales, quien buscaba un cuarto mandato. La concentración del poder tiene mucho que ver con la expropiación de la fuerza, de la energía colectiva, que los movimientos sociales ilustraron cabalmente al inicio del período progresista, pero que luego fue concentrado en la persona del líder. Recuerdo que en 2007 o 2008 ganó un concurso de documentales de CLACSO, cuyo título era "Hartos Evos hay". Esto quería decir: "hay muchos Evos", porque, efectivamente, hay muchos líderes que surgen desde abajo. Difícilmente el 2015 o 2016 podamos repetir esa frase, antes bien, son muchos los que piensan que "Evo hay uno solo". Evo es el que, efectivamente, dirige ese proceso político y tiene severas dificultades para generar espacios democráticos alrededor de su persona.

En ese sentido, el populismo implica, también, un control tutelado de las masas, un modelo de participación controlada desde el Estado, que se puede hacer con mayor o menor presión, según los casos, pero que en todos los países, sea en Ecuador, sea en Bolivia, sea en Argentina, sea en Venezuela, se ha dado con claridad. Se trata de un proceso de resubalternización de las organizaciones sociales en un esquema más bien vertical en donde domina la figura del líder. Esto es evidente en el avance sobre aquellos sectores que critican las políticas gubernamentales, sean ONG críticas, sean movimientos u organizaciones sociales, sean intelectuales, encontramos una inflexión fuerte en términos de clausura por parte de estos gobiernos populistas.

A esto cabe añadir varias precisiones. Una de ellas es que hay diversos tipos de populismo. No es lo mismo el régimen que encontramos en Argentina y Ecuador, que es un populismo típico de clases medias empoderadas que hablan en nombre de los sectores populares - un populismo que no es antielitista - que el populismo en Venezuela o en Bolivia, que es un populismo plebeyo que se ha expresado —según las fases - en una fuerte democratización del poder. No olviden ustedes que hace 12 años en Bolivia gobernaban 12 familias. Hoy, efectivamente, hay una democratización del poder; sin embargo, en esa tensión con los elementos, más bien autoritarios o de clausura, lo que vemos claramente es que el gobierno de Evo Morales tiene una fuerte tentación hegemonista que implica, cada vez, mayor concentración del poder y mayor intolerancia a las disidencias.

\section{Comentarios finales en clave geopolítica. Latinoamericano y su vínculo con China}

Hay dos temas de carácter geopolítico, respecto de las limitaciones de los gobiernos progresistas. El primero tiene que ver con las limitaciones del regionalismo desafiante, y el segundo tiene que ver con la vinculación con China.

\section{2/ REVISTA DESSOCOLOGGíA 26}


Sin duda a lo largo de estos 15 años los progresismos en América Latina han implicado la emergencia de un espacio latinoamericano diferente. El hecho de que estemos hablando acá, de esta manera, da cuenta de la socialización de ciertas categorías y de ciertos procesos políticos comunes, más allá de las diferencias importantes a nivel nacional. En consecuencia, podemos reconocer que emergió desde temprano, lo que denomina el mexicano Jaime Preciado Coronado, como un regionalismo desafiante que tiene su punto culminante, su punto de inflexión con el "No al ALCA" en el año 2005 en Mar del Plata, en Argentina, el cual fue un proceso que se fue construyendo con anterioridad, con los movimientos sociales en Paraguay, en Brasil, en Argentina, en Bolivia, un proceso que se articuló desde abajo con los nuevos liderazgos regionales ${ }^{8}$. Evo Morales todavía no era presidente, ahí estuvo Lula da Silva que tenía un fuerte protagonismo regional, y por supuesto Hugo Chávez. Ahí hubo, realmente, una fuerte articulación desde abajo y desde arriba que sirvió para decir NO al ALCA, al Tratado de Libre Comercio con los Estados Unidos, con Bush presente en esa ocasión. Sabemos que luego se crearon distintas instituciones a nivel latinoamericano, desde el ALBA, la UNASUR, luego la CELAC, el Banco del Sur que nunca funcionó a ciencia cierta. En mi opinión, el NO al ALCA del 2005 debió convertirse en un punto de partida para la construcción de un regionalismo diferente, de un bloque regional desafiante con capacidad de negociar desde otro lugar con otros países; sin embargo, éste no fue el punto de partida, no fue la base sino más bien fue el techo del regionalismo latinoamericano desafiante, porque posteriormente lo que hubo fue la constitución de un UNASUR de baja intensidad en la cual los líderes daban largos discursos sin la presencia de los movimientos sociales y esos discursos latinoamericanistas tenían poco correlato con la realidad. El caso es que, efectivamente, ese bloque desafiante nunca se constituyó como tal más allá de ciertas acciones importantes (como con Bolivia, cuando el nuevo gobierno de Morales se enfrentó a la oligarquía cruceña). Hacia el 2011, surgió la Alianza del Pacífico que comienza a competir con el bloque de países progresistas, en un momento de anunciación del declive de los gobiernos progresistas.

La otra cuestión de índole geopolítico tiene que ver con los vínculos económicos con China. China es la gran fábrica del mundo: 1300 millones de habitantes; un proceso fabuloso de migración del campo a la ciudad, un proceso de urbanización que, sin duda, tiene mucho que ver con el aporte que América Latina está haciendo de materias primas hacia el gran país asiático. Aparecen, entonces, grandes debates en América Latina en los últimos cinco o seis años sobre el rol que ocuparía China en

8 Preciado Coronado, Jaime. "Paradigma social en debate; aportaciones del enfoque geo-político crítico. La CELAC en la integración autónoma de América Latina", en Marta Nélida (Coord.). América Latina en la crisis global. Problemas y desafíos. México: CLACSO. 2013. 
relación a nuestra región. Para algunos intelectuales, China serviría de contrapeso a la influencia de Estados Unidos. En esa línea, sería posible establecer una suerte de Cooperación Sur-Sur con China; sin embargo, la realidad nos dice otra cosa. Los hechos nos muestran que hay un proceso de transición en la cual hay una disputa interhegemónica entre Estados Unidos y China por los distintos mercados y zonas de influencia. A partir de 2007 se han intensificado la relación de los países latinoamericanos con China, para lo cual nuestra región exporta materias primas o commodities e importa productos manufacturados o de alto valor agregado desde China. Es decir, en realidad estamos consolidando con China un vínculo cada vez más asimétrico; y China también está utilizando, en ese proceso de transición hegemónica, la alianza con América Latina. Pero, en realidad, no es una alianza que América Latina realice en términos regionales. En ese caso, de haber desarrollado un regionalismo desafiante América Latina podría haberse constituido como bloque regional y podría hoy negociar con China en diferentes condiciones. Sin embargo, nuestros países compiten entre sí. Nuestros países han celebrado convenios con China de manera unilateral que sólo aventajan a China y poco a nuestros países, a los cuales se los compromete, también, mediante la firma de esos convenios económicos-financieros, por largas décadas. China viene invirtiendo en la región en minería, en petróleo, en agronegocios, en megarrepresas. En todo caso, China apuntala el efecto de reprimarización de la economía que hay en América Latina, porque lo que hace es exigir sólo materias primas, no productos manufacturados o de valor agregado. Inclusive esto afecta a un país como Brasil que está mucho más diversificado económicamente que otros países de la región, a través de la exportación que este país hace de soja y de hierro. Si esto impacta en Brasil, imagínense cómo lo hace en países monoproductores o especializados en la exportación de ciertas materias primas. Y, si a eso le añadimos que muchos de esos convenios no son conocidos en la letra chica, sino que están amparados por una suerte de secretismo, vemos que, efectivamente, los convenios con China están consolidando una suerte de neodependencia.

Estamos en un fin de ciclo. El 2013 empieza el fin del súper ciclo de los commodities, lo cual, lejos de implicar la salida del extractivismo, ha exacerbado aún más las actividades extractivas, porque los países necesitan, en ese sentido, reforzar inclusive el extractivismo para tener las mismas ganancias, los mismos beneficios fiscales que tenían en el momento del alto precio de los commodities. Ello nos hace pensar que a futuro es más probable la profundización del extractivismo y una mayor criminalización de las luchas que se oponen a la expansión de estas actividades.

Por otro lado, en el juego de las oposiciones muchos de los progresismos han logrado monopolizar el espacio de la centroizquierda, obturando la posibilidad de la emergencia de otras posiciones críticas, de otras posibilidades progresistas. Esto es lo

\section{4/ REVISTA DE SOCIOLOGíA 26}


que sucedió en Argentina. El arribo por la vía electoral de la derecha en la Argentina, no responde a la derechización de la sociedad argentina, sino que se derechizó la oferta política partidaria en un momento de búsqueda de alternancia por parte de la sociedad. Los argentinos estuvimos obligados a votar entre dos candidatos de derecha. Entre un candidato de derecha que representaba al progresismo y un candidato de la derecha neoempresarial, quien ganó, porque representaba la posibilidad de la alternancia. Pero mucha de la responsabilidad de estos escenarios derechizados en términos políticos tiene que ver con esa tendencia al hegemonismo propia de los progresismos en los últimos tiempos. Por supuesto que esto, en un contexto de final de ciclo que hemos visto, al menos en Argentina, también lo estamos viendo en Brasil $y$, probablemente en Venezuela, deja un fuerte sabor amargo al realizar un balance del ciclo progresista. Recuerden ustedes Evo Morales no tiene la posibilidad de ser re-reelegido, y tampoco Rafael Correa en Ecuador. Asimismo, son muchas las heridas abiertas en el campo político-intelectual latinoamericano.

No obstante, yo considero que hay un legado organizacional, que hay líneas de acumulación de luchas en el ámbito socioterritorial, entre las luchas socioambientales y también entre las luchas socioculturales que constituyen, sin duda, el acervo fundamental de las clases subalternas en América Latina, que nos llevarán a pensar desde otro lugar, pero siempre desde la izquierda, desde la idea de transformación social, el posprogresismo que se viene. Muchas gracias. 